\title{
Plasma concentrations of adrenomedullin and atrial and brain natriuretic peptides in patients with adrenal pheochromocytoma
}

\author{
WEI HU $^{1 *}$, LEI SHI $^{2 *}$, PANG-HU ZHOU ${ }^{3}$ and XIAO-BIN ZHANG ${ }^{1}$ \\ Departments of ${ }^{1}$ Urology, ${ }^{2}$ Oncology and ${ }^{3}$ Orthopedics, Renmin Hospital of Wuhan University, \\ Wuhan, Hubei 430060, P.R. China
}

Received October 26, 2014; Accepted August 5, 2015

DOI: 10.3892/ol.2015.3660

\begin{abstract}
The present study aimed to evaluate any changes in the plasma concentrations of adrenomedullin (ADM), atrial natriuretic peptide (ANP) and brain natriuretic peptide (BNP) in patients with adrenal pheochromocytoma (PC). The plasma concentrations of the three peptides were measured in 45 healthy control individuals and 90 untreated patients with PC, who consisted of 20 normotensive patients, 30 borderline hypertensive patients and 40 hypertensive patients. After 4 weeks of effective antihypertensive therapy for hypertensive PC patients, the concentrations of ADM, ANP and BNP were measured again, and laparoscopic adrenalectomy was then performed for all PC patients with values that were measured 2 weeks later. The plasma concentrations of the three peptides were significantly increased in the borderline hypertensive and hypertensive patients compared with the concentrations in control individuals and normotensive patients. In addition, there were significant differences between the levels of ADM, ANP and BNP in the borderline and hypertensive groups. The plasma ADM concentration was not associated with the blood urea nitrogen levels, serum creatinine levels or glomerular filtration rate, but was correlated with the serum epinephrine, serum norepinephrine and urine vanillylmandelic acid levels. In addition, the ADM concentration was associated with the systolic blood pressure, diastolic blood pressure, left ventricular ejection fraction, left ventricular mass index and plasma concentrations of ANP and BNP in the hypertensive patients with PC. After 4 weeks of antihypertensive treatment, the values of the three peptides in the hypertensive patients with PC were not significantly changed. As expected, the values in borderline and hypertensive groups were significantly
\end{abstract}

Correspondence to: Dr Pang-Hu Zhou, Department of Orthopedics, Renmin Hospital of Wuhan University, 238 Liberation Road, Wuhan, Hubei 430060, P.R. China

E-mail: zhoupanghu@126.com

*Contributed equally

Key words: adrenomedullin, atrial natriuretic peptide, brain natriuretic peptide, adrenal, pheochromocytoma decreased 2 weeks subsequent to surgery, whereas there were no significant changes in the normotensive group. ADM may participate, along with ANP and BNP, in the mechanisms that counteract further elevation of blood pressure in patients with $\mathrm{PC}$, and there may be an ADM/catecholamine local regulatory mechanism that is important for the control of adrenal medulla functions.

\section{Introduction}

Pheochromocytoma (PC) is a rare neuroendocrine tumor that originates from the adrenal medulla or chromaffin cells of the sympathetic ganglia, and the tumor is characterized by the excessive production of catecholamines $(1,2)$. In addition to catecholamines, PC may also participate in homeostatic regulations by producing numerous peptides, including adrenomedullin (ADM), which was first isolated from acid extracts of human PC tissue and was subsequently found to be a circulating hormone (3-5). The synthesis and release of ADM may be affected by physical factors, including shear stress, ventricular wall stress and hypoxia, and humoral factors, including cytokines, endocrine hormones and paracrine hormones (6). Following the release from diverse tissues, ADM acts as an autocrine or a paracrine hormone to play an important role in the stress response, including the regulation of vascular tone and blood pressure (5,7). ADM exerts biological effects directly through cyclic adenosine monophosphate (cAMP) and indirectly through endothelial nitric oxide (8).

The natriuretic peptide system, including atrial natriuretic peptide (ANP) and brain natriuretic peptide (BNP), may locally and systemically regulate blood pressure and oxygen transport by causing volume contraction through natriuresis, diuresis and plasma shift, leading to hemoconcentration and an increased oxygen-carrying capacity per unit volume of blood to counteract hypoxic conditions (9-12). Certain studies performed using cultured cardiomyocytes, particularly from rodents, have demonstrated that the expression of the ANP and BNP genes may be regulated by several factors, including catecholamines and certain cytokines (13). Numerous cardiovascular diseases, including chronic heart failure, systemic hypertension, coronary disease and endothelial dysfunction, are responsible for the raised secretion of ANP and BNP (14). ANP and BNP are mainly synthesized and released by atrial and ventricular myocytes, respectively, and exert biological 
actions through the accumulation of intracellular cyclic guanosine monophosphate (15), whereas the actions of ADM are mainly mediated by cAMP (16). The three peptides demonstrate similar pathophysiological functions, despite differences in the intracellular signaling systems, and the expression of the ANP and BNP genes may be regulated by ADM. Therefore, it was hypothesized that ADM functions along with ANP and BNP to counteract the additional elevation of blood pressure in patients with PC.

To evaluate any changes in the plasma concentrations of $\mathrm{ADM}, \mathrm{ANP}$ and BNP in patients with PC, the plasma levels of the three peptides were measured in untreated patients with $\mathrm{PC}$ and the results were compared with those obtained from healthy control individuals. The levels of ADM, ANP and BNP in hypertensive patients with PC were measured subsequent to 4 weeks of effective antihypertensive therapy. Laparoscopic adrenalectomy was then performed on all PC patients, and the values were measured 2 weeks later. The results prior to and following treatment were compared.

\section{Patients and methods}

Patients. Between February 2006 and November 2013, 45 healthy control individuals (mean age, $44.3 \pm 7.3$ years; range, 31-59 years) and 90 PC patients (mean age, $44.8 \pm 8.1$ years; range, 32-59 years) were recruited for the present study from Renmin Hospital of Wuhan University (Wuhan, Hubei, China). The PC patients consisted of 20 normotensive patients (mean age, 45.0 \pm 6.6 years; range, $32-58$ years), 30 borderline hypertensive patients (mean age, $43.0 \pm 7.5$ years; range, $32-54$ years) and 40 hypertensive patients (mean age, $46.0 \pm 9.1$ years; range, 33-59 years). This study has been approved by the Ethics Committee of Renmin Hospital of Wuhan University, and was performed in adherence with the China Association for Ethical Studies guidelines. All subjects agreed to participate in the present study and provided written informed consent.

The routine laboratory and radiological assessments of all patients were as follows: Assays of blood routine tests; urinalysis; measurement of serum electrolytes and fasting blood glucose levels; liver and kidney function tests; assessment of plasma renin activity, aldosterone, catecholamine, cortisol and thyroid hormone levels; measurement of the 24-h urine vanillylmandelic acid (VMA) level; chest roentgenogram; electrocardiogram; and B-scan ultrasonography of the abdomen, including the liver, cholecyst, pancreas, spleen, kidneys and adrenal glands. The glomerular filtration rate (GFR) was calculated by measuring serum cystatin $C$, as previously described (17). Additional radiological studies included one or more of the following diagnostic methods: Magnetic resonance imaging; computed tomography (CT); positron emission tomography (PET) imaging with fluorodeoxyglucose; dihydroxyphenylalanine-PET-CT; Octreoscan; and ${ }^{123} \mathrm{I}$-metaiodo-benzylguanidine scintigraphy. A familial history of multiple endocrine neoplasia syndrome was ruled out in all patients. Symptomatic adrenal PC was definitely diagnosed on the basis of clinical manifestations, such as hypertension, tachycardia, dizziness, flushing, tremor, pallor, headache, palpitations, sweating, feelings of panic or anxiety and excessive catecholamine excretion, and the aforementioned imaging examinations. Asymptomatic adrenal PC was an incidentaloma that was identified during a checkup, and the diagnosis was confirmed by a number of the aforementioned imaging examinations. In all PC patients, imaging examinations revealed unilateral solid masses with apparently benign features.

Post-operative histopathological findings of the extirpated tumors at surgery were obtained. According to the current guidelines (18), normal BP was defined as a systolic pressure $<140 \mathrm{mmHg}$ and a diastolic pressure $<90 \mathrm{mmHg}$. Hypertension was defined as a systolic pressure $\geq 160 \mathrm{mmHg}$ or a diastolic pressure $\geq 100 \mathrm{mmHg}$, or the two together. The term borderline hypertension was used to denote BP values between the normal and hypertensive ranges, as aforementioned. None of the present patients demonstrated clinical evidence of cardiac or hepatic failure, diabetes, pulmonary disease, angina pectoris, myocardial infarction, essential hypertension or other diseases that may result in secondary hypertension. No PC patients had undergone previous antihypertensive drug treatment, or the antihypertensive therapy had been discontinued at least 2 weeks prior to the present study. The healthy control individuals were age- and gender-matched normotensive subjects that had been hospitalized for a routine checkup.

Subsequent to the initial evaluation, 40 hypertensive PC patients commenced antihypertensive therapy with $10-30 \mathrm{mg}$ phenoxybenzamine twice a day. The plasma concentrations of $\mathrm{ADM}, \mathrm{ANP}$ and BNP were determined prior to the initiation of therapy and subsequent to 4 weeks of effective antihypertensive treatment. Transperitoneal laparoscopic adrenalectomy was then performed in all PC subjects that were suitable for surgery. Subsequent to 2 weeks, the therapeutic effect was estimated with the normalization of catecholamine hypersecretion and complete disappearance of symptoms, as well as the reduction or abstention of antihypertensive therapy in symptomatic PC patients. In addition, the values of the three peptides were measured in all PC patients.

Arterial blood pressure was measured using ambulatory blood pressure monitoring for at least two weeks. The results were analyzed using Microsoft Excel software, version 2007 (Microsoft Corporation, Redmond, WA, USA) and the mean of the blood pressure measurements was used.

Preparations of human ADM, ANP and BNP. Blood samples were obtained early in the morning, between 08:00 and 09:00, following an overnight fast. An intravenous catheter was inserted into the antecubital vein when the subject was in the supine position. Plasma samples were collected in tubes, centrifuged at $1,600 \mathrm{x}$ g for $10 \mathrm{~min}$ at $4^{\circ} \mathrm{C}$, and then immediately frozen and stored in polypropylene tubes at $-80^{\circ} \mathrm{C}$ prior to use in the assays.

Hormone measurements. The plasma ADM concentrations were measured by a specific radioimmunoassay (RIA; ADM RIA Shionogi; Shionogi Pharmaceutical Co., Ltd., Osaka, Japan), as described previously (19). Briefly, $2 \mathrm{ml}$ of plasma was applied to a Sep-Pak C18 cartridge (Waters Corporation, Milford, MA, USA) and the column was sequentially washed using $5 \mathrm{ml}$ isotonic saline, $5 \mathrm{ml} 0.1 \%$ trifluoroacetic acid (TFA) and $5 \mathrm{ml} \mathrm{20 \%}$ acetonitrile in $0.1 \%$ TFA. The ADM was then eluted with $4 \mathrm{ml} 60 \%$ acetonitrile in $0.1 \%$ TFA, lyophilized and then stored at $-80^{\circ} \mathrm{C}$ until the radioassay was performed. The 
Table I. Clinical profiles of control subjects and patients with PC.

\begin{tabular}{|c|c|c|c|c|}
\hline \multirow[b]{2}{*}{ Parameters } & \multirow[b]{2}{*}{ Control } & \multicolumn{3}{|c|}{ PC patient group } \\
\hline & & Normotensive & Borderline & Hypertensive \\
\hline Total & 45 & 20 & 30 & 40 \\
\hline Age, years & $44.3 \pm 7.3$ & $45.0 \pm 6.6$ & $43.0 \pm 7.5$ & $46.0 \pm 9.1$ \\
\hline Gender, male:female & $26: 19$ & $12: 8$ & $17: 13$ & $24: 16$ \\
\hline $\mathrm{SBP}, \mathrm{mmHg}$ & $121.0 \pm 10.0$ & $120.0 \pm 9.0$ & $150.0 \pm 6.0^{\mathrm{a}, \mathrm{b}}$ & $177.0 \pm 10.0^{\mathrm{a}-\mathrm{c}}$ \\
\hline DBP, mmHg & $78.0 \pm 5.0$ & $79.0 \pm 6.0$ & $92.0 \pm 1.0^{\mathrm{a}, \mathrm{b}}$ & $107.0 \pm 6.0^{\mathrm{a}-\mathrm{c}}$ \\
\hline BUN, mg/dl & $17.0 \pm 2.0$ & $18.0 \pm 3.0$ & $18.0 \pm 4.0$ & $22.0 \pm 5.0^{\mathrm{a}-\mathrm{c}}$ \\
\hline Scr, mg/dl & $1.0 \pm 0.2$ & $1.1 \pm 0.3$ & $1.1 \pm 0.5$ & $1.5 \pm 0.6^{\mathrm{a}-\mathrm{c}}$ \\
\hline $\mathrm{GFR}, \mathrm{ml} / \mathrm{min}$ & $98.0 \pm 9.0$ & $96.0 \pm 8.0$ & $95.0 \pm 10.0$ & $82.0 \pm 14.0^{\mathrm{a}-\mathrm{c}}$ \\
\hline Serum E, pg/ml & $64.0 \pm 16.0$ & $73.0 \pm 28.0$ & $203.0 \pm 81.0^{\mathrm{a}, \mathrm{b}}$ & $462.0 \pm 141.0^{\mathrm{a}-\mathrm{c}}$ \\
\hline Serum NE, pg/ml & $208.0 \pm 64.0$ & $246.0 \pm 123.0$ & $751.0 \pm 238.0^{\mathrm{a}, \mathrm{b}}$ & $1280.0 \pm 518.0^{\mathrm{a}-\mathrm{c}}$ \\
\hline Urine VMA, mg/24 h & $4.0 \pm 2.0$ & $5.0 \pm 2.0$ & $13.0 \pm 5.0^{\mathrm{a}, \mathrm{b}}$ & $21.0 \pm 9.0^{\mathrm{a}-\mathrm{c}}$ \\
\hline LVEF, \% & $84.0 \pm 7.0$ & $82.0 \pm 6.0$ & $77.0 \pm 8.0^{\mathrm{a}, \mathrm{b}}$ & $72.0 \pm 10.0^{\mathrm{a}-\mathrm{c}}$ \\
\hline LVMI, $\mathrm{g} / \mathrm{m}^{2}$ & $114.0 \pm 6.0$ & $117.0 \pm 7.0$ & $128.0 \pm 10.0^{\mathrm{a}, \mathrm{b}}$ & $140.0 \pm 12.0^{\mathrm{a}-\mathrm{c}}$ \\
\hline
\end{tabular}

The normal values for catecholamines are as follows: Serum E, 0-100 pg/ml; serum NE, 0-600 pg/ml; urine VMA, 1-7 mg/24 h. ${ }^{\text {aP }}<0.05$ compared with the control group; ${ }^{b} \mathrm{P}<0.05$ compared with the normotensive group; ${ }^{\mathrm{C}} \mathrm{P}<0.05$ compared with the borderline hypertensive group. PC, pheochromocytoma; SBP, systolic blood pressure; DBP, diastolic blood pressure; BUN, blood urea nitrogen; Scr, serum creatinine; GFR, glomerular filtration rate; E, epinephrine; NE, norepinephrine; VMA, vanillylmandelic acid; LVEF, left ventricular ejection fraction; LVMI, left ventricular mass index.

residue was then dissolved in $300 \mu \mathrm{l}$ RIA buffer, $50 \mathrm{mmol} / 1$ sodium phosphate buffer ( $\mathrm{pH} 7.4$ ) containing $0.5 \%$ bovine serum albumin (BSA), 0.5\% Triton X-100, $80 \mathrm{mmol} / 1$ sodium chloride, $25 \mathrm{mmol} / 1 \mathrm{EDTA}, 0.05 \%$ sodium azide and $500 \mathrm{KIU} / \mathrm{ml}$ aprotinin. In total, $100 \mu \mathrm{l}$ of the dissolved plasma extract was subjected to a specific RIA for human ADM, as previously reported (19). According to the manufacturer's instructions, the rabbit polyclonal antibody (cat no. G-010-01, Phoenix Pharmaceuticals Inc., Burlingame, CA, USA) against human ADM $1-52$ at a final dilution of 1:3,200, cross-reacts completely with human $\operatorname{ADM}(1-52)$, but not with rat $\operatorname{ADM}(1-50)$, human amylin, human CGRP, calcitonin, $\alpha$-human atrial natriuretic peptide-(1-28), brain natriuretic peptide-32, C-type natriuretic peptide-22 or neuropeptide Y. All assays were performed three times, and the mean of the three measurements was used. The detection limit was $0.5 \mathrm{pmol} / \mathrm{l}$ and the working range $(\mathrm{CV}$ $<15 \%$ ) was $1-300 \mathrm{pmol} / \mathrm{l}$. The interassay coefficient of variation was $3.4-7.8 \%$, and the intraassay coefficient of variation was 5.6-8.9\%. All assays were performed in duplicate. Concentrations of ADM were expressed in $\mathrm{pmol} / \mathrm{l}$.

The plasma ANP and BNP concentrations were measured with specific immunoradiometric assays for human ANP and BNP (ShionoRlA ANP and BNP kits; Shionogi Pharmaceutical Co., Ltd.). The accuracies and detailed methods for these assays have been described previously (20).

Statistical analysis. All continuous data were expressed as the mean \pm standard deviation and analyzed using SPSS software, version 19.0 (SPSS Inc., Chicago, IL, USA). Comparisons between the groups were performed using analysis of variance, followed by the Student-Newman-Keuls test. Categorical variables were assessed by the $\chi^{2}$ test or Fisher's exact test.
Stepwise multiple linear regression analysis was used to identify the most important determinant for blood pressure or serum catecholamines. The correlations between variables were determined by simple linear regression analysis and then confirmed using the Pearson product-moment correlation coefficient. Comparisons between two independent variables were performed using an unpaired $t$-test. Comparisons between paired values were performed using a paired $t$-test. Data that were not normally distributed were assessed using the Mann-Whitney $\mathrm{U}$ test. $\mathrm{P}<0.05$ was considered to indicate a statistically significant difference.

\section{Results}

Clinical characteristics of control individuals and patients with PC. Table I reports the clinical profiles of the control individuals and patients with PC. There were no significant differences between the age and gender distribution of the four groups. As expected, the mean SBP and DBP values were significantly higher in borderline and hypertensive patients with PC compared with the mean values of the control individuals and normotensive patients with $\mathrm{PC}(\mathrm{P}<0.05)$. In addition, significant differences were present between the SBP and DBP values of borderline and hypertensive patients. Similar changes were observed between the mean serum epinephrine (E) and norepinephrine (NE), urine VMA, left ventricular ejection fraction (LVEF) and left ventricular mass index (LVMI) values in the four groups. However, the mean blood urea nitrogen (BUN) and serum creatinine (Scr) levels and GFR were only significantly higher in the hypertensive patients with PC compared with the values in the other three groups, between which no significant differences were found. 


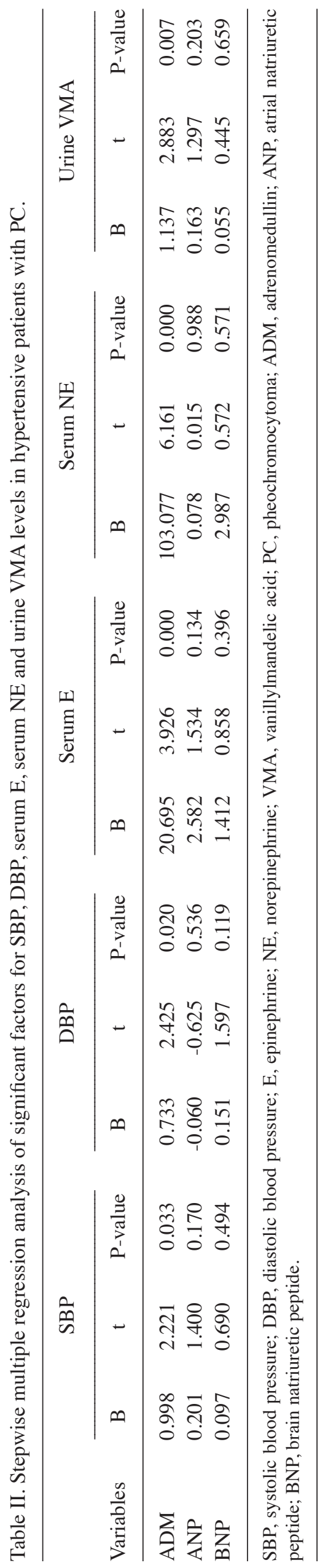

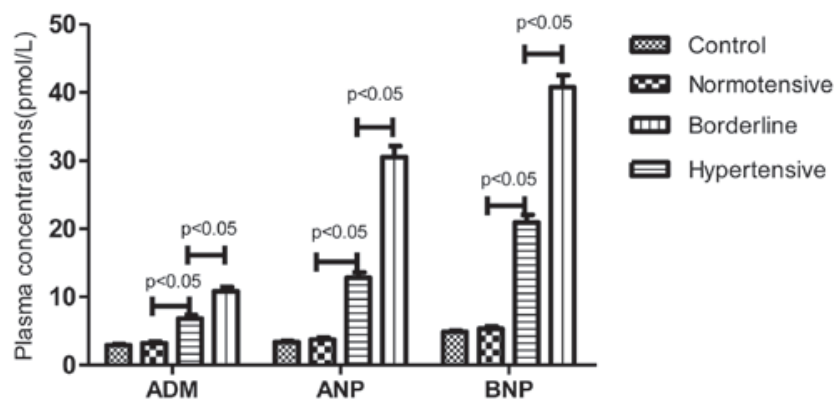

Figure 1. Plasma concentrations of ADM, ANP and BNP in the control and three PC subgroups. PC, pheochromocytoma; ADM, adrenomedullin; ANP, atrial natriuretic peptide; BNP, brain natriuretic peptide.

$A D M, A N P$ and BNP concentrations in subgroups of $P C$ patients. The plasma concentrations of ADM, ANP and BNP in the control and three PC subgroups are shown in Fig. 1. The mean ADM values were significantly higher in the borderline and hypertensive patients with PC $(6.86 \pm 2.65$ and $10.84 \pm 4.07 \mathrm{pmol} / 1$, respectively) compared with the values in the control individuals $(2.93 \pm 0.74 \mathrm{pmol} / \mathrm{l})$ and normotensive PC patients $(3.25 \pm 1.10 \mathrm{pmol} / \mathrm{l})(\mathrm{P}<0.05)$. There was also a significant difference between the values in the borderline and hypertensive patients $(\mathrm{P}<0.05)$. The mean ANP levels in the control and $3 \mathrm{PC}$ subgroups groups were $3.41 \pm 1.04$, $3.77 \pm 1.24,12.82 \pm 4.41,30.52 \pm 10.39 \mathrm{pmol} / 1$, respectively, while the mean BNP levels were $4.91 \pm 1.02,5.35 \pm 1.43,20.92 \pm 6.34$, $40.78 \pm 11.29 \mathrm{pmol} / \mathrm{l}$, respectively. Similar changes were observed between the mean ANP and BNP levels in the four groups.

Association between plasma ADM concentrations and clinical parameters. Table II reveals that ADM was the most important factor associated with the blood pressure, serum catecholamine levels or urine VMA levels in hypertensive patients with PC. Stepwise multiple regression analysis was performed on the independent parameters associated with the SBP, DBP, serum E, serum NE and urine VMA values, to identify which was the most important factor in hypertensive PC patients.

The scatterplots in Fig. 2 demonstrate the association between plasma ADM concentrations and BUN, Scr, serum E, serum NE and urine VMA levels and GFR in hypertensive patients with PC. The plasma ADM concentrations were not correlated with the BUN or Scr levels or GFR, but the concentrations were associated with the serum $\mathrm{E}$, serum $\mathrm{NE}$ and urine VMA levels $(\mathrm{P}<0.05)$.

The scatterplots in Fig. 3 demonstrate the correlations between the plasma ADM concentrations and the SBP, DBP, LVEF, LVMI, ANP and BNP values in hypertensive PC patients. Plasma ADM concentrations were positively correlated with the SBP, DBP, LVMI, ANP and BNP values, but negatively correlated with the LVEF values $(\mathrm{P}<0.05)$.

Association between ADM, ANP and BNP levels and renal function. The plasma concentrations of ADM, ANP and BNP were also analyzed in hypertensive patients with PC, with or without renal dysfunction. There were no significant differences in the plasma concentrations between patients 
Table III. Hemodynamic parameters of hypertensive patients with PC $(n=40)$.

Time of sample collection

\begin{tabular}{lccc} 
& At diagnosis & After drugs & After surgery \\
\cline { 2 - 4 } Parameters & $177.0 \pm 10.0$ & $150.0 \pm 4.0^{\mathrm{a}}$ & $120.0 \pm 10.0^{\mathrm{a}, \mathrm{b}}$ \\
$\mathrm{DBP}, \mathrm{mmHg}$ & $107.0 \pm 6.0$ & $95.0 \pm 3.0^{\mathrm{a}}$ & $80.0 \pm 6.0^{\mathrm{a}, \mathrm{b}}$ \\
$\mathrm{BUN}, \mathrm{mg} / \mathrm{dl}$ & $22.0 \pm 5.0$ & $21.0 \pm 5.0$ & $23.0 \pm 6.0$ \\
Scr, $\mathrm{mg} / \mathrm{dl}$ & $1.5 \pm 0.6$ & $1.4 \pm 0.5$ & $1.6 \pm 0.6$ \\
GFR, $\mathrm{ml} / \mathrm{min}$ & $82.0 \pm 14.0$ & $84.0 \pm 15.0$ & $80.0 \pm 12.0$ \\
Serum E, pg/ml & $462.0 \pm 141.0$ & $483.0 \pm 158.0$ & $70.0 \pm 18.0^{\mathrm{a}, \mathrm{b}}$ \\
Serum NE, pg/ml & $1280.0 \pm 518.0$ & $1345.0 \pm 603.0$ & $226.0 \pm 104.0^{\mathrm{a}, \mathrm{b}}$ \\
Urine VMA, mg/24 h & $21.0 \pm 9.0$ & $22.0 \pm 10.0$ & $4.0 \pm 1.0^{\mathrm{a}, \mathrm{b}}$ \\
LVEF, $\%$ & $72.0 \pm 10.0$ & $74.0 \pm 6.0$ & $80.0 \pm 5.0^{\mathrm{a}, \mathrm{b}}$ \\
LVMI, g/m & $140.0 \pm 12.0$ & $136.0 \pm 11.0$ & $120.0 \pm 7.0^{\mathrm{a}, \mathrm{b}}$
\end{tabular}

${ }^{a} \mathrm{P}<0.05$ compared with subjects at diagnosis; ${ }^{b} \mathrm{P}<0.05$ compared with subjects after drugs. PC, pheochromocytoma; SBP, systolic blood pressure; DBP, diastolic blood pressure; BUN, blood urea nitrogen; Scr, serum creatinine; GFR, glomerular filtration rate; E, epinephrine; NE, norepinephrine; VMA, vanillylmandelic acid; LVEF, left ventricular ejection fraction; LVMI, left ventricular mass index.
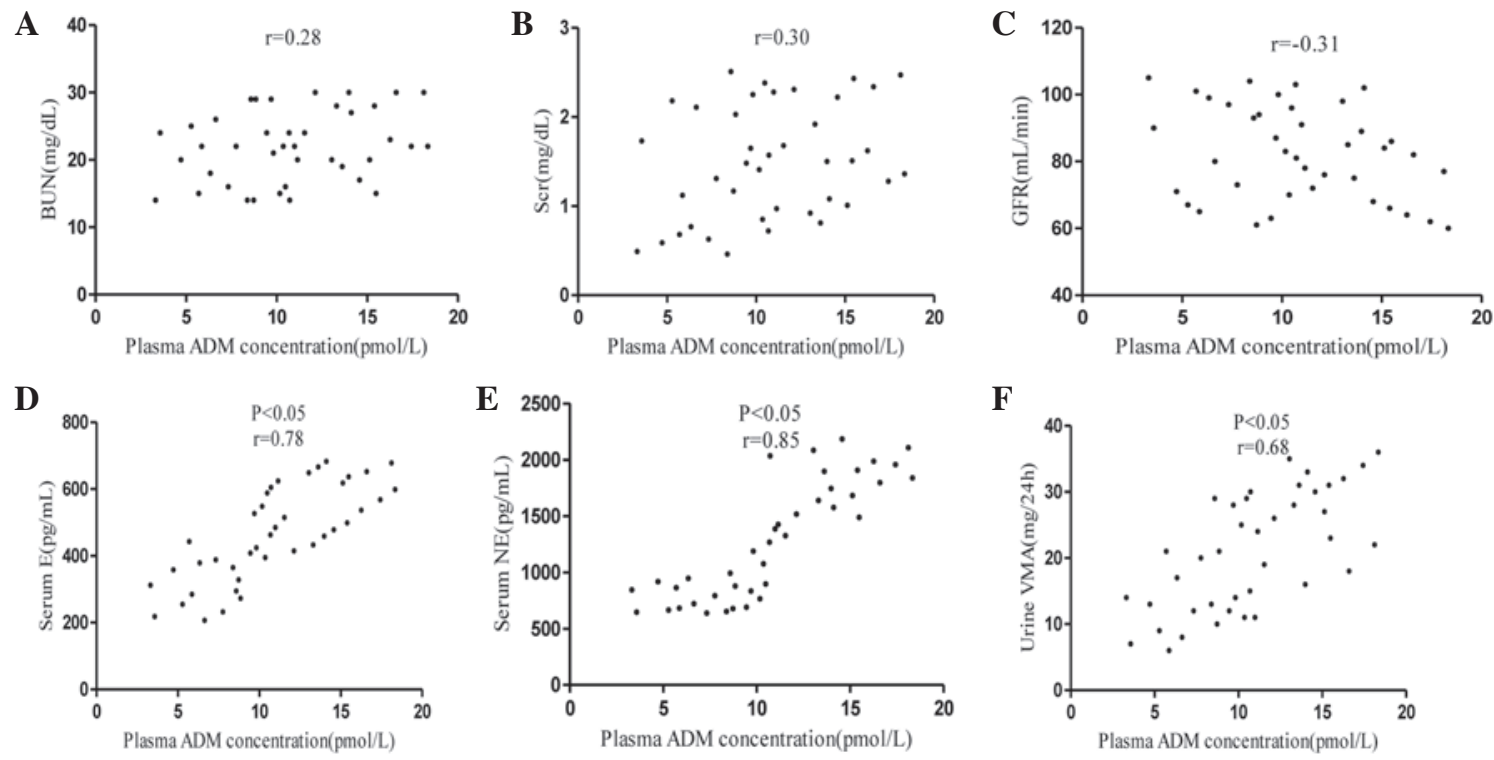

Figure 2.Association between the plasma ADM concentrations and (A) BUN, (B) Scr, (C) GFR, (D) serum E, (E) serum NE and urine (F) VMA in hypertensive patients with pheochromocytoma. BUN, blood urea nitrogen; Scr, serum creatinine; GFR, glomerular filtration rate; E, epinephrine; NE, norepinephrine; VMA, vanillylmandelic acid; ADM, adrenomedullin.

with renal dysfunction, which was indicated by a Scr level $\geq 1.5 \mathrm{mg} / \mathrm{dl}$ or GFR $\leq 80 \mathrm{ml} / \mathrm{min}$, and subjects without renal dysfunction, which was indicated by a Scr level $<1.5 \mathrm{mg} / \mathrm{dl}$ or GFR $>80 \mathrm{ml} / \mathrm{min}$. However, the concentrations of the three peptides in patients with or without renal dysfunction were increased compared with the concentration in the control individuals $(\mathrm{P}<0.05)$ (data not shown).

Hemodynamic parameters of hypertensive PC patients. Table III reports the clinical parameters of hypertensive patients with $\mathrm{PC}$ at the time of diagnosis, subsequent to drug treatment and following surgery. The SBP and DBP were significantly decreased subsequent to drug treatment $(\mathrm{P}<0.05)$, but were within the normal range following surgery $(\mathrm{P}<0.05$;
SBP $<140 \mathrm{mmHg}$ and DBP $<90 \mathrm{mmHg}$ ). The BUN and Scr levels and GFR were not significantly changed. The serum E, serum NE, urine VMA, LVEF and LVMI values were not significantly changed subsequent to drug treatment, but were within the normal range following surgery $(\mathrm{P}<0.05$; Table I).

Changes in ADM, ANP and BNP concentrations following drug treatment and surgery. The bars in Fig. 4 indicate the initial plasma concentrations of ADM, ANP and BNP and the concentrations 4 weeks subsequent to effective antihypertensive therapy or 2 weeks subsequent to surgery in the three PC subgroups. The plasma concentrations of ADM, ANP and BNP in the normotensive group were not significantly different prior to $(3.25 \pm 1.10,3.77 \pm 1.24$ and $5.35 \pm 1.43 \mathrm{pmol} / \mathrm{l}$, 
A
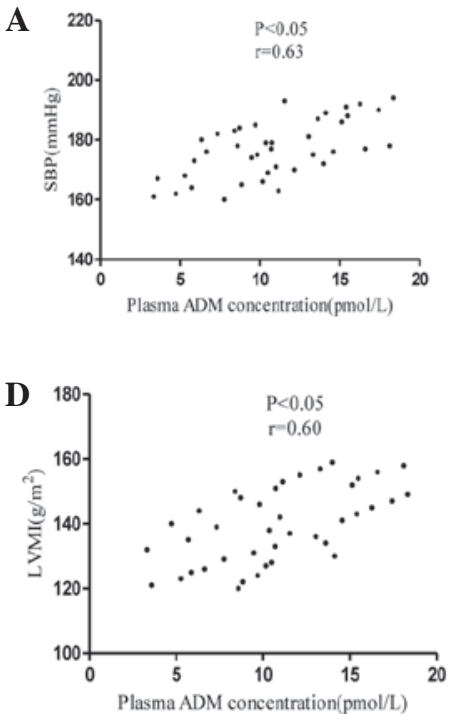
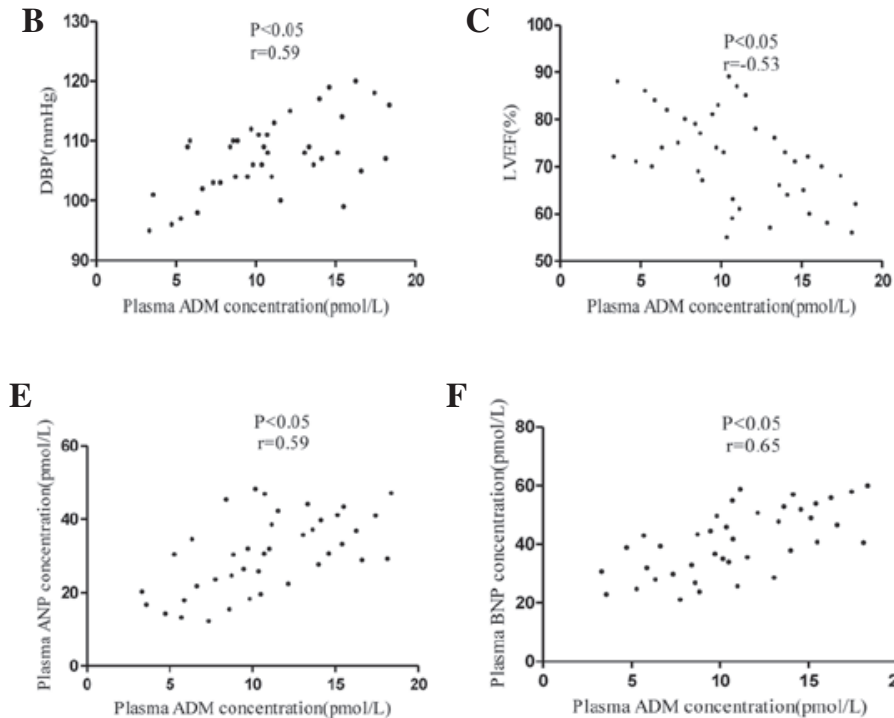

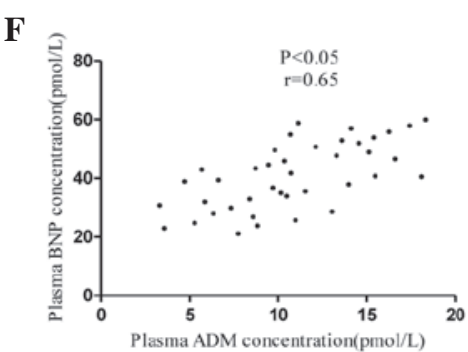

Figure 3. Association between the plasma ADM concentrations and (A) SBP, (B) DBP, (C) LVEF, (D) LVMI, (E) ANP and (F) BNP levels in hypertensive patients with pheochromocytoma. SBP, systolic blood pressure; DBP, diastolic blood pressure; LVEF, left ventricular ejection fraction; LVMI, left ventricular mass index; ADM, adrenomedullin; ANP, atrial natriuretic peptide; BNP, brain natriuretic peptide.
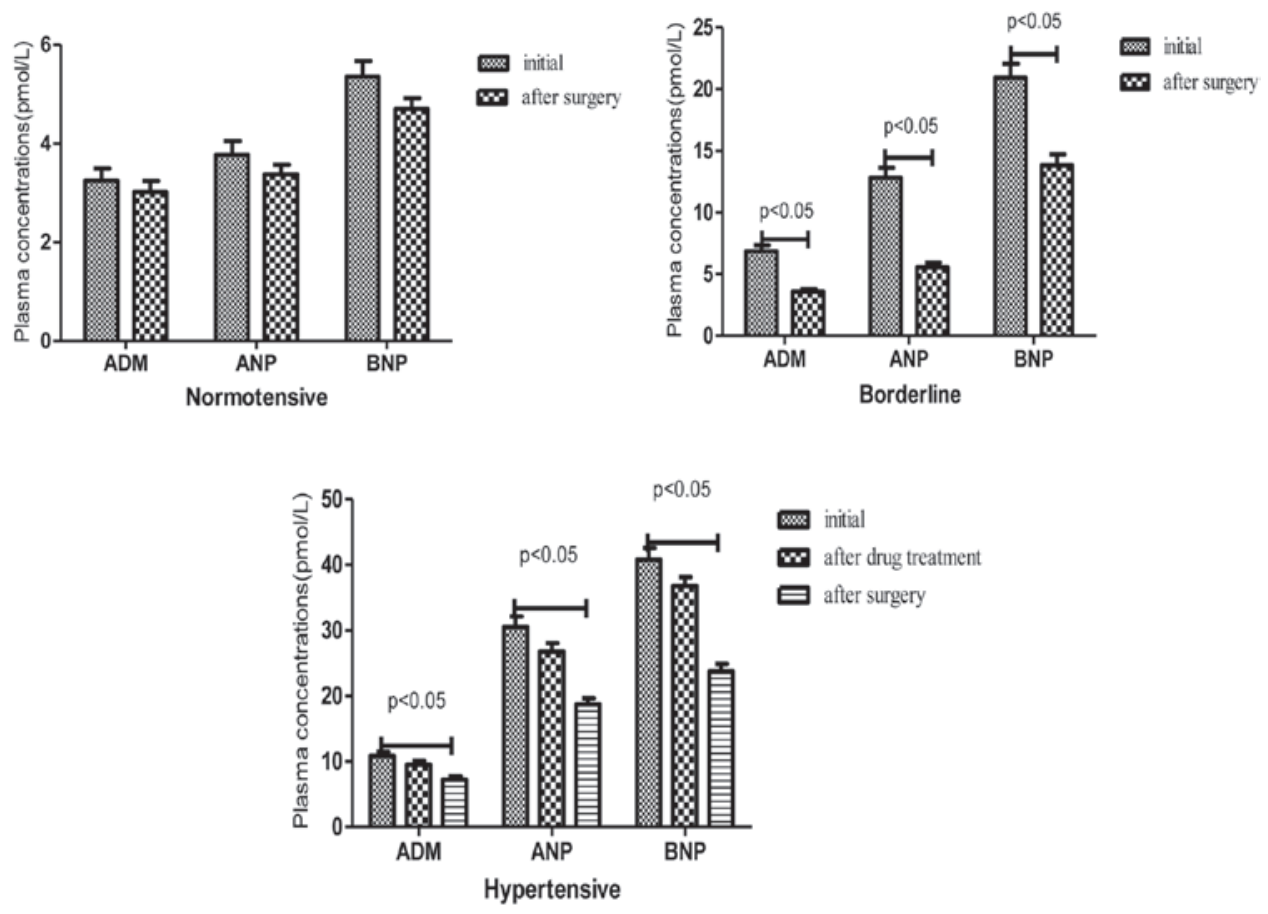

Figure 4. The plasma concentrations of ADM, ANP, and BNP initially, 4 weeks after effective antihypertensive therapy and 2 weeks after surgery in hypertensive patients with pheochromocytoma. ADM, adrenomedullin; ANP, atrial natriuretic peptide; BNP, brain natriuretic peptide.

respectively) and following surgery $(3.02 \pm 1.01,3.38 \pm 0.86$ and $4.70 \pm 0.98 \mathrm{pmol} / \mathrm{l}$, respectively). The plasma concentrations in the borderline group were significantly decreased subsequent to surgery $(3.60 \pm 1.03,5.55 \pm 2.05$ and $13.82 \pm 4.86 \mathrm{pmol} / 1$, respectively) compared with the concentrations prior to surgery $(6.86 \pm 2.65,12.82 \pm 4.41$ and $20.92 \pm 6.34$, respectively) $(\mathrm{P}<0.05)$. The values of the three peptides in the hypertensive group were not significantly decreased subsequent to drug treatment $(9.52 \pm 3.60,26.78 \pm 8.03$ and $36.76 \pm 8.81 \mathrm{pmol} / 1$, respectively $)$ compared with the values prior to drug treatment $(10.84 \pm 4.07$, $30.52 \pm 10.39$ and $40.78 \pm 11.29$, respectively). However, the concentrations were significantly decreased following surgery $(7.24 \pm 3.02,18.73 \pm 5.86$ and $23.73 \pm 7.27 \mathrm{pmol} / 1$, respectively) compared with the values prior to surgery $(10.84 \pm 4.07$, $30.52 \pm 10.39$ and $40.78 \pm 11.29$, respectively $(\mathrm{P}<0.05)$.

\section{Discussion}

$\mathrm{PC}$ is a rare neuroendocrine tumor with a highly variable clinical presentation, but this tumor most commonly presents with episodes of hypertension due to the potent effects of the catecholamines secreted by the tumor, such as dopamine, E and 
NE, and this may result in high oxygen consumption (21-23). Although hypertension is the hallmark of catecholamine release and may result in serious and potentially lethal cardiovascular complications, the amount, type and pattern of catecholamine secretion is extremely variable (24). Blood pressure may also be consistently normal, particularly in patients with adrenal incidentalomas or in those with extremely small tumors (25). ADM is a peptide expressed in the cardiovascular system that often demonstrates increased expression prior to the development of hypertension $(26,27)$. Increased circulating levels of ADM have previously been associated with the LVMI and left ventricular hypertrophy, and are considered to be an independent risk factor for cardiovascular disease (28-31). ANP and BNP are each similar to ADM in cardiovascular effects, including natriuresis, diuresis, hypotensive action and anti-hypertrophic action, thereby reducing fluid volume and increasing oxygen transport $(32,33)$. Numerous previous studies have demonstrated that the plasma levels of ADM, ANP and BNP are elevated in patients with essential hypertension $(27,34)$.

In the present study, significantly increased mean BUN and Scr levels and decreased mean GFRs were noted in hypertensive patients with PC compared with the control, normotensive and borderline patients with PC. Therefore, it is likely that secondary hypertension resulting from PC may lead to renal dysfunction when hypertension is severe enough. Furthermore, the BUN and Scr levels and GFRs were unchanged subsequent to the administration of drugs or surgery. This may be due to certain long-standing or elderly patients that possessed slightly irreversible renal damage. Nevertheless, significantly decreased LVEF and increased LVMI values were found in hypertensive patients with PC compared with the values in control individuals and normotensive and borderline hypertensive patients with PC. In addition, the LVEF and LVMI values in the normotensive and borderline hypertensive groups were significantly different. The LVEF and LVMI values were unchanged subsequent to the administration of drugs, but were significantly decreased following surgery (27,34-36). Therefore, the changes in cardiac function may not only be due to secondary hypertension, but also due to catecholamine cardiomyopathy. It is necessary to clarify these results in additional studies.

In accordance with previous studies, the plasma levels of ADM, ANP and BNP identified in the current study were increased in hypertensive patients with PC compared with the levels in the control individuals and normotensive and borderline hypertensive patients with PC. The present data appear to be compatible with the previous studies by Letizia et al and Cotesta et al $(35,36)$. In addition, significant differences were found between the plasma levels of ADM, ANP and BNP in the normotensive and borderline hypertensive patients with PC, but were not observed between control individuals and normotensive patients with $\mathrm{PC}$. The most likely explanation is that normotensive PC patients are challenging to diagnose, as there is no catecholamine hypersecretion. Significant differences in the levels of serum E, serum NE and urine VMA were found between borderline and hypertensive PC patients, but were not observed between controls and normotensive PC patients. By contrast, it may be inferred that ADM, in addition to ANP and BNP, may participate in the compensatory and protective mechanisms that counteract additional elevation of blood pressure in the cardiovascular system, due to the similar physiological roles. The plasma concentrations of ADM were not only correlated with the SBP and DBP values, but were also associated with the values of ANP and BNP in hypertensive PC patients. Furthermore, ADM was identified as the most important factor in hypertensive PC patients, which was confirmed by stepwise multiple regression analysis of the independent parameters associated with SBP, DBP, serum E, serum NE or urine VMA levels. There may be an interactive balance mechanism of ADM and catecholamines in the adrenal medulla. However, elevated values of the three peptides in hypertensive PC patients were not associated with renal function, which was confirmed by the lack of differences between the peptide levels in patients with or without renal dysfunction. In addition, ADM levels were not correlated with the BUN level, Scr level or GFR of patients.

The present study revealed that the elevated values of the peptides ADM, ANP and BNP were not significantly decreased subsequent to anti-hypertensive treatment, but did significantly decline following surgery in hypertensive PC patients. In addition, the values significantly fell in borderline hypertensive PC patients following surgery. It has been demonstrated that catecholamines may increase myocardial oxygen consumption and lead to cardiomyopathy (37). It is likely that there is an ADM/catecholamine regulatory mechanism that may also regulate the secretion of ANP and BNP. The plasma ADM concentration may predict catecholamine hypersecretion. Plasma ADM concentrations were not only correlated with the values of serum E, serum NE and urine VMA, but were also associated with the ANP and BNP levels. Furthermore, plasma ADM concentrations were correlated with the values of LVEF and LVMI. Therefore, ADM may participate, along with ANP and BNP, in the defense mechanisms in an attempt to increase oxygen transport to satisfy the high oxygen consumption that results from catecholamine hypersecretion and normalize the state of cardiovascular health in patients with PC.

As aforementioned, a number of investigations have revealed increased plasma ADM levels in patients with PC $(35,36)$. However, to the best of our knowledge, the present study is the first to assess plasma ADM, ANP and BNP levels in patients with $\mathrm{PC}$ that were classified into normotensive, borderline and hypertensive groups, and also compared the concentrations of the three peptides in hypertensive PC patients prior to and following drug treatment.

In summary, the present study reveals that ADM, ANP and BNP may participate in the mechanisms that counteract the additional elevation of blood pressure and increase oxygen transport to satisfy the high oxygen consumption in PC. However, these peptides may be good predictors of catecholamine hypersecretion and hypertension improvement in patients with PC. In addition, there may be an $\mathrm{ADM} /$ catecholamine local regulatory mechanism that is important for the control of adrenal medulla functions. However, additional studies are required to identify the specific pathophysiological significance of ADM, ANP and BNP in PC and the exact pharmacokinetics of these peptides in patients with $\mathrm{PC}$. 


\section{Acknowledgements}

This study was supported by grants from the National Science Fund Project of China (grant no. 81200501) and the Doctor Research Fund Project of Wuhan University of China (grant no. 2012302020203). Thanks to the Department of Urology in Renmin Hospital of Wuhan University.

\section{References}

1. Shen WT, Grogan R, Vriens M, Clark OH and Duh QY: One hundred two patients with pheochromocytoma treated at a single institution since the introduction of laparoscopic adrenalectomy. Arch Surg 145: 893-897, 2010.

2. Domi R and Laho H: Management of pheochromocytoma: Old ideas and new drugs. Niger J Clin Pract 15: 253-257, 2012.

3. Thouennon E, Pierre A, Yon L and Anouar Y: Expression of trophic peptides and their receptors in chromaffin cells and pheochromocytoma. Cell Mol Neurobiol 30: 1383-1389, 2010.

4. Kitamura K, Kangawa K, Kawamoto M, Ichiki Y, Nakamura S, Matsuo H and Eto T: Adrenomedullin: A novel hypotensive peptide isolated from human pheochromocytoma. 1993. Biochem Biophys Res Commun 425: 548-555, 2012.

5. Wong HK, Cheung TT and Cheung BM: Adrenomedullin and cardiovascular diseases. JRSM Cardiovasc Dis 1: pii, 2012.

6. Cheung BM and Tang F: Adrenomedullin: Exciting new horizons. Recent Pat Endocr Metab Immune Drug Discov 6: 4-17, 2012.

7. Shimosawa T and Fujita T: Adrenomedullin and its related peptide. Endocr J 52: 1-10, 2005

8. Nishikimi T, Kuwahara K, Nakagawa Y, Kangawa $\mathrm{K}$ and Nakao K: Adrenomedullin in cardiovascular disease: A useful biomarker, its pathological roles and therapeutic application. Curr Protein Pept Sci 14: 256-267, 2013.

9. Arjamaa $\mathrm{O}$ and Nikinmaa $\mathrm{M}$ : Natriuretic peptides in hormonal regulation of hypoxia responses. Am J Physiol Regul Integr Comp Physiol 296: R257-R264, 2009.

10. Arjamaa $\mathrm{O}$ and Nikinmaa M: Hypoxia regulates the natriuretic peptide system. Int J Physiol Pharmacol 3: 191-201, 2011.

11. Arjamaa $\mathrm{O}$ and Nikinmaa M: Oxygen and natriuretic peptide secretion from the heart. Int J Cardiol 167: 1089-1090, 2013.

12. Arjamaa O: Physiology of natriuretic peptides: The volume overload hypothesis revisited. World J Cardiol 6: 4-7, 2014.

13. Clerico A, Giannoni A, Vittorini S and Passino C: Thirty years of the heart as an endocrine organ: Physiological role and clinical utility of cardiac natriuretic hormones. Am J Physiol Heart Circ Physiol 301: H12-H20, 2011.

14. Federico C: Natriuretic Peptide system and cardiovascular disease. Heart views 11: 10-15, 2010.

15. Kuhn M: Endothelial actions of atrial and B-type natriuretic peptides. Br J Pharmacol 166: 522-531, 2012.

16. Lu WW and Qi YF: Cardiovascular effects and pathophysiological significance of adrenomedullin family peptides. Sheng Li Ke Xue Jin Zhan 44: 177-182, 2013; (In Chinese).

17. Chollet-Dallon E, Stoermann-Chopard C and Martin PY: Could cystatine $\mathrm{C}$ replace creatinine as a market of glomerular filtration rate? Revue medicale suisse 2: 582-585, 2006.

18. Mancia G, De Backer G, Dominiczak A, Cifkova R, Fagard R, Germano G, Grassi G, Heagerty AM, Kjeldsen SE, Laurent S, et al: 2007 Guidelines for the management of arterial Hypertension: The task force for the management of arterial hypertension of the european society of hypertension (ESH) and of the European Society of Cardiology (ESC). J Hypertens 25: 1105-1187, 2007.

19. Ohta H, Tsuji T, Asai S, Tanizaki S, Sasakura K, Teraoka H, Kitamura $\mathrm{K}$ and Kangawa K: A simple immunoradiometric assay for measuring the entire molecules of adrenomedullin in human plasma. Clin Chim Acta 287: 131-143, 1999.
20. Grzywa-Celińska A, Celiński R, Kwaśniewska K, Dyczko M, Prystupa A and Mosiewicz J: The usefulness of natriuretic peptides measurements in the diagnostics of chosen cardiovascular diseases. Pol Merkur Lekarski 34: 232-234, 2013 (In Polish).

21. Lenders JW, Eisenhofer G, Mannelli M and Pacak K: Phaeochromocytoma. Lancet 366: 665-675, 2005.

22. Miller RA and Ohrt DW: Pheochromocytoma - review and biochemical workup. S D Med 66: 267 269-270, 2013.

23. Marín MR, Arenas MF, Valverde FM, Garaulet ET, Maderuelo MM, Avilés AM, Quirante FP and Blázquez AA: Laparoscopic adrenalectomy for nonfamilial adrenal medullary hyperplasia. JSLS 17: 433-439, 2013.

24. Mannelli M, Lenders JW, Pacak K, Parenti G and Eisenhofer G: Subclinical phaeochromocytoma. Best practice \& research. Best Pract Res Clin Endocrinol Metab 26: 507-515, 2012.

25. Bovio S, Cataldi A, Reimondo G, Sperone P, Novello S, Berruti A, Borasio P, Fava C, Dogliotti L, Scagliotti GV, et al: Prevalence of adrenal incidentaloma in a contemporary computerized tomography series. J Endocrinol Invest 29: 298-302, 2006

26. Bełtowski J and Jamroz A: Adrenomedullin-what do we know 10 years since its discovery?. Pol J Pharmacol 56: 5-27, 2004.

27. Kato J, Kitamura K and Eto T: Plasma adrenomedullin level and development of hypertension. J Hum Hypertens 20: 566-570, 2006.

28. Al-Omari MA, Khaleghi M, Mosley TH Jr, Turner ST, Morgenthaler NG, Struck J, Bergmann A and Kullo IJ: Mid-regional pro-adrenomedullin is associated with pulse pressure, left ventricular mass and albuminuria in African Americans with hypertension. Am J Hypertens 22: 860-866, 2009.

29. Bhandari SS, Davies JE, Struck J and Ng LL: The midregional portion of proadrenomedullin is an independent predictor of left ventricular mass index in hypertension. Metabolism 59: 7-13, 2010.

30. Coutinho T, Al-Omari M, Mosley TH Jr and Kullo IJ: Biomarkers of left ventricular hypertrophy and remodeling in blacks. Hypertension 58: 920-925, 2011

31. Nishida H, Horio T, Suzuki Y, Iwashima Y, Kamide K, Kangawa $\mathrm{K}$ and Kawano Y: Plasma adrenomedullin as an independent predictor of future cardiovascular events in high-risk patients: Comparison with C-reactive protein and adiponectin. Peptides 29: 599-605, 2008

32. Sergeeva IA and Christoffels VM: Regulation of expression of atrial and brain natriuretic peptide, biomarkers for heart development and disease. Biochim Biophys Acta 1832: 2403-2413, 2013.

33. Saito Y: Roles of atrial natriuretic peptide and its therapeutic use. J Cardiol 56: 262-270, 2010.

34. Soualmia H, Ayadi I, Omar S, Feki M, Drissa H, Mebazaa A and Kaabachi N: Atrial natriuretic peptide and brain natriuretic peptide release in human essential hypertension. Clin Lab 55: 120-127, 2009.

35. Letizia C, De Toma G, Caliumi C, Cerci S, Massa R, Loria RD, Alo P, Marinoni EM, Diacinti D and D'Erasmo E: Plasma adrenomedullin concentrations in patients with adrenal pheochromocytoma. Horm Metab Res 33: 290-294, 2001.

36. Cotesta D, Caliumi C, Alò P, Petramala L, Reale MG, Masciangelo R, Signore A, Cianci R, D'Erasmo E and Letizia C: High plasma levels of human chromogranin A and adrenomedullin in patients with pheochromocytoma. Tumori 91: 53-58, 2005.

37. Vindenes T, Crump N, Casenas R and Wood K: Pheochromocytoma causing cardiomyopathy, ischemic stroke and acute arterial thrombosis: A case report and review of the literature. Conn Med 77: 95-98, 2013. 